\section{Genetic variability and breeding potential of Flintisa Composite of maize in two levels of technology}

\section{João Antonio da Costa Andrade ${ }^{1^{*}}$}

Abstract: The purpose this study was to verify the breeding potential of Flintisa Composite for low (LT) and high (HT) technology of cultivation, and the best selection strategy to be adopted. For this reason half-sib progenies were evaluated in the two technological levels. In HT, it was used basic fertilization, two top dressing and supplementary irrigation. In $L T$, these practices were suppressed, and less fertile soil was used. Except for grain yield (GY), heritability was high at plant level and at progenies mean level. With mass selection, estimated gains ranged from 3.3\% (GY in LT) to $41.8 \%$ (tassel branches number in LT). For half-sib selection, estimated gains ranged from $4.7 \%$ (plant height in HT) to 23.6\% (erect plants in HT). For ear height, stratified mass selection in just one environment should be valid for both. Half-sib selection, with $S_{1}$ recombination should be adopted in specific selection programs for LT and HT.

Keywords: heritability, genetic additive variance, selection, genotype x environment interaction.

\section{INTRODUCTION}

Obtaining cultivars with good agronomic potential requires continuous selection programs. In these breeding programs, the knowledge of the genetic variability in the population is of great interest for breeders, since variability is fundamental for the success of a selection work. Once every observation that is made on a quantitative trait consists of a genetic and a non-genetic (environmental) component, the variance of this trait is also composed of genetic and environmental variances. The former is used in selection, and the latter is not, and it goes against the breeder's interest (Vencovsky 1987).

The decision on the best improvement method, on the proper selection intensity, and on the traits to be considered in the selection is based on the knowledge of the genetic structure of the population. Therefore, the estimate of genetic parameters, such as additive genetic variance, variance of the progeny $x$ environment interaction, heritability, and expected progress with selection is one of the first steps to be taken in a breeding program (Singh et al. 2018), and it should be carried out in various environments, if possible. The genotype $x$ environment interaction may hinder selection in breeding for various environments. Its magnitude will indicate if it is necessary to use separate selection programs. In the case where the environment differs on technology levels, it is possible to obtain important information on the breeding potential of populations, in order to obtain more responsive and/or more rustic varieties.
Crop Breeding and Applied Biotechnology 19: 145-152, 2019 Brazilian Society of Plant Breeding. Printed in Brazil http://dx.doi.org/10.1590/198470332019v19n2a21 
For the second case, the efforts are justified in studies aimed to obtain cultivars with greater ability to take advantage of the naturally available resources, or that are offered in insufficient amount, such as soil nutrients.

The process of genetic parameter estimation was made feasible, developed and widely used for several schemes of genetic mating and genetic-statistical procedures (Falconer and Mackay 1996, Hallauer et al. 2010, Khan et al. 2018). Over the selection cycles, this procedure helps in the checking, from time to time, of the evolution of genetic variability and the need for changes in the selection process (Freitas Júnior et al. 2009). Large ranges of values in the genetic parameter estimates are reported for the traits studied in this work, as well as other traits that make part of yield components in Brazilian maize populations (Candido and Andrade 2008, Andrade and Miranda Filho 2008, Faluba et al. 2010, Reis et al. 2014) and semi-exotic populations (Oliveira et al. 2015, Souza et al. 2018).

This study aimed to verify the genetic variability and the potential of Flintisa Composite for breeding in high and low cultivation technology environments, and the best selection strategy to be adopted.

\section{MATERIAL AND METHODS}

Flintisa Composite was obtained by the recombination of the populations Esalq - VF 1, Suwan and Cateto Colombia. It was subjected to six selection cycles for yield. The first, the second, the fourth and sixth cycles were carried out based on stratified mass selection. The third selection cycle was carried out between half-sib, and the fifth cycle was carried out between half-sib progenies with $\mathrm{S}_{1}$ progenies recombination. All selection cycles were carried out without any fertilizer, and were considered as low technology environment.

In this study, it was used 223 half-sib progenies with their respective $S_{1}$ progenies, taken from prolific plants of the population obtained after the sixth selection cycle in Flintisa Composite. Half-sib progenies were evaluated in eight experiments set in high-tech environment (soil of average fertility, with fertilizer according to soil analysis, and under supplementary irrigation). Of this total, 191 progenies were also evaluated in eight experiments in low-tech environment (less fertile soil, without fertilization and without irrigation), as shown in Table 1 . The $\mathrm{S}_{1}$ progenies were stored as remnant seed, aiming at the recombination of progenies selected by the method of selection between half-sib, with recombination of inbred progenies.

All experiments were carried out in a randomized block design with three replications, in the agricultural year of 2010/11, in Selvíria-MS (lat $20^{\circ} 20^{\prime} \mathrm{S}$, long $51^{\circ} 21^{\prime} \mathrm{W}$, and alt $335 \mathrm{~m}$ asl). The high-tech environment experimental plot consisted of a $4 \mathrm{~m}$ row with 20 plants, spaced $20 \mathrm{~cm}$ apart. In the low-tech environment, plots consisted of a $4.28 \mathrm{~m}$ row, with 20 plants spaced $21.4 \mathrm{~cm}$ apart. In both cases, the spacing between rows (plot) was $85 \mathrm{~cm}$. The commercial hybrids, P30F80 and C 929, were used as controls in the high-tech experiments, and the hybrids AG519 and Master were used as control in the low-tech experiments. The change in the controls was due to their different adaptability. The hybrids P30F80 and C929 are recommended for high-tech farms, whereas the hybrids AG 519 and Master are more rustic, and thus are recommended for low-tech farms.

In the high-tech environment it was used a fertilization of $250 \mathrm{~kg} \mathrm{ha}^{-1}$ of the formula 8-28-16, at sowing, and two top dressings. In the first (at the stage of 4 to 5 developed leaves), it was applied $300 \mathrm{~kg} \mathrm{ha}^{-1}$ of the formula 20-00-15, and in the second (at the stage of 6 to 7 developed leaves), $140 \mathrm{~kg} \mathrm{ha}^{-1}$ of urea. The population of 58,800 plants ha-1 was used since most commercial cultivars recommended for high technology adopt population around 60,000 plants ha-1. This is also because fertilization was carried out aiming at a yield of about $8 \mathrm{t} \mathrm{ha}^{-1}$, and because the experiment was set under the central pivot. The low-tech environment was primarily characterized by a little less fertile soil (Table 1), and by the absence of fertilization, which also led to the use of a smaller plant population (55,000 plants ha-1).

Table 1. Chemical analysis of the soil where the experiments of maize progenies were carried out

\begin{tabular}{|c|c|c|c|c|c|c|c|c|}
\hline \multirow{2}{*}{ Technology level } & \multirow{2}{*}{$\begin{array}{l}\text { P-resin } \\
\mathrm{mg} \mathrm{cm}^{-3}\end{array}$} & \multirow{2}{*}{$\begin{array}{c}\text { O.M. } \\
(\%)\end{array}$} & \multirow{2}{*}{$\begin{array}{l}\mathbf{p H} \text { in } \\
\mathrm{CaCl}_{2}\end{array}$} & $\mathbf{K}^{+}$ & $\mathrm{Ca}^{++}$ & $\mathrm{Mg}^{++}$ & $\left(\mathrm{H}^{+}+\mathrm{Al}^{+++}\right)$ & \multirow{2}{*}{$\begin{array}{c}\mathrm{V} \\
(\%) \\
\end{array}$} \\
\hline & & & & \multicolumn{4}{|c|}{ Meq $\mathrm{cm}^{-3}$} & \\
\hline High-tech & 16 & 2.8 & 4.8 & 0.23 & 2.1 & 1.6 & 3.8 & 51 \\
\hline
\end{tabular}


The following variables were analyzed in the trials: Plant height (PH) - measured in $\mathrm{m}$, from the ground level to the bottom of the flag leaf sheath (mean of five competitive plants in the plot); Ear height (EH) - measured in $m$, from the ground level to the insertion of the upper ear (mean of five competitive plants in the plot); Tassel branches number (TB) - obtained by simple counting, as the mean of five competitive plants in the plot; Erect plants (EP) - percentage of plants that did not fall in relation to the final stand of the plot; Grain yield (GY) - measured in kg as the total of the plot, adjusted to $13 \%$ moisture, and to ideal stand of 20 plants per plot, by analysis of covariance (Vencovsky and Barriga 1992).

The experiments were analyzed individually, grouped for each technology level and jointly, involving both technology levels. Data from individual plants were used to calculate separately the mean square within plots, whereas the plots means were used to calculate the other mean squares of the analysis of variance, except for GY, for which total plots were used. Analysis of covariance was carried out between variables in order to obtain estimates of phenotypic and additive covariance, and the coefficients of phenotypic and genetic additive correlations. For this purpose, all variables, except for GY, were considered as plot means. For the estimates, the environment factor was considered as fixed, and the progenies factor was considered as random, according to Vencovsky and Barriga (1992).

Based on the expectations of mean squares and mean products, the following parameters were estimated for each technology level and/or joint analysis (Vencovsky and Barriga 1992): a) Phenotypic variance within progenies for PH, $\mathrm{EH}$ and TB. For GY, the within phenotypic variance was considered to be 10 times the environmental variance between plots, as suggested by Gardner (1961); b) Environmental variance between plots; c) Genetic variance between progenies; d) Variance of the progenies $x$ technology levels interaction; e) Phenotypic variance at plant level; f) Mean phenotypic variance; g) Additive genetic variance; h) Coefficient of heritability for selection based on individual plants; i) Coefficient of heritability for selection based on progeny means; j) Expected gain with mass selection for one sex; $k$ ) Expected gain with selection between and within half-sib progenies, for two and one sex, respectively; I) Environmental covariance; m) Covariance between progenies; n) Additive genetic covariance; o) Mean phenotypic covariance; p) Coefficient of phenotypic correlation; q) Coefficient of additive genetic correlation; r) Correlated response with mass selection in one sex; s) Correlated response with selection between and within half-sib progenies, for two and one sex, respectively.

\section{RESULTS AND DISCUSSION}

Most of the coefficients of variation of the experiments were below $20 \%$, except for EP in high-tech environment. This suggests good accuracy of the results for progeny trials, which is in accordance with the literature (Scapim et al. 1995). EP is related to lodged plants, and in this sense, the high coefficients of variation are also in agreement with the literature. Also, the ratio between the highest and lowest residual mean square was lower than 7 for all traits, indicating the possibility of carrying out grouped and joint analyses of variance for each environment (Pimentel-Gomes and Garcia 2002).

The first evidence of genetic variability is noticed by significant $F$ test for progenies $(p<0.01)$ for all traits in the grouped analyses in both environments and in joint analysis (Table 2). In high-tech environments, plants had higher means for $\mathrm{PH}$ and $\mathrm{EH}$, and lower means for EP (higher incidence of lodging), compared to low-tech environment. Compared to the controls, progenies means were 7.8 and $16.4 \%$ higher for plant and ear height, respectively (18.9 and $22.4 \mathrm{~cm}$ higher). On the other hand, EP in progenies was $41.1 \%$ lower than in controls. This is normally associated with plant and ear heights, since, in most populations, there is positive correlation between these traits and lodging (Candido and Andrade 2008), and it is also associated to the fact that controls are selected for less lodging and breakage. Thus, it would be expected that the correlation of $\mathrm{PH}$ and EH with EP is negative. This did not occur in the present study, since correlations were close to zero (Table 4). In this case, poor quality of stem and high density of plants might have contributed to the difference between progenies and controls. In low-tech environment, EP difference was not so high, and progenies presented $12.5 \%$ less EP than controls. Although correlations were not high, plants were shorter in low-tech than in high-tech environment.

For GY, progenies mean was below the controls mean in both environments. Differences were $31.6 \%$ and $34.8 \%$, in high and low-tech environments, respectively (Table 2). However, in both environments, it was observed that the best progenies were similar to controls.

Estimates of additive variance (Table 3) were high for $\mathrm{PH}\left(279.8\right.$ and $\left.355.1\left(\mathrm{~cm} \mathrm{pl}^{-1}\right)^{2}\right)$ and EH $\left(207.9\right.$ and $\left.209\left(\mathrm{~cm} \mathrm{pl}^{-1}\right)^{2}\right)$, 
when compared with data presented by Candido and Andrade (2008), Andrade and Miranda Filho (2008), Hallauer et al. (2010) and Faluba et al. (2010) and similar to estimates by Souza et al. (2018). For GY, the estimate of $588.1\left(\mathrm{~g} \mathrm{pl}^{-1}\right)^{2}\left(\mathrm{high}^{-}\right.$ tech environment) was superior to the mean found by Hallauer et al. (2010) and Reis et al. (2014), similar to estimates by Souza et al. (2018) for the populations CRE-1 and CRE-2, but lower than the estimate found by Faluba et al. (2010) for UFV 7 population $\left(622.7\left(\mathrm{~g} \mathrm{pl}^{-1}\right)^{2}\right)$. For TB, the additive variances were 21.9 (high-tech) and 34.7 (branches $\left.\mathrm{l}^{-1}\right)^{2}\left(\right.$ (low- $^{-}$ tech), close to that obtained by Souza Júnior et al. (1985) (28.55), Souza et al. (2018) (19.29 and 18.9) and higher than that obtained by Andrade and Miranda Filho (2008) (13.57 (branches $\left.\left.\mathrm{pl}^{-1}\right)^{2}\right)$.

Heritability coefficients (Table 3) were high both at individuals level and means level, for PH, EH, TB and EP. For GY, heritability at mean level (56\% in high-tech and $41.7 \%$ in low-tech) was 3.8 and 4.9 times higher than at plant level. Heritability of these magnitudes was also found by Andrade and Miranda Filho (2008), Candido and Andrade (2008), Faluba et al. (2010) and Souza et al (2018). Araújo et al. (2005) also obtained similar estimate for the population CMS 39, evaluated at $0.9 \mathrm{~m}$ spacing (44.6\%), and lower estimates at $0.5 \mathrm{~m}$ spacing (29.5\%). For PH, EH and GY, Shahrokhi et al. (2013) and Carvalho et al. (2003) obtained similar estimates in populations ksc 704, CMS 47, BR 5011, CMS 35 and CPATC-3. Under nitrogen stress conditions, Soares et al. (2011) found heritability of $82 \%, 72 \%$ and $83 \%$, respectively, for PH, EH and GY, in a population originated from the crossing between two tropical inbred lines.

In low-tech environment, EP also presented high heritability at mean level. However, the expected gain was $44.7 \%$ lower when compared to high-tech environment (Table 3), although, in absolute terms, gains were similar in both environments. This is because the mean was $53.3 \%$ higher, and the heritabilities were similar.

According to the expected gains (Table 3), it appears that PH, EH and TB may be easily modified with mass selection. Even using the $\mathrm{S}_{1}$ progenies recombination, in which it is expected that gain with selection between half-sibs are duplicated (Vencovsky 1987), mass selection should still be preferred. The expected gains with mass selection in EH were $12.6 \%$

Table 2. Means, coefficients of variation and means squares (MS) of the grouped and joint analyses of variance for plant height (PH), ear height (EH), tassel branches number (TB), percentage of erect plants (EP) and grain yield (GY) of maize

\begin{tabular}{|c|c|c|c|c|c|c|}
\hline S.V. & df & $\mathrm{PH}(\mathrm{cm})$ & $\mathrm{EH}(\mathrm{cm})$ & TB & EP (\%) & GY $\left(\mathrm{kg} \mathrm{plot}^{-1}\right)$ \\
\hline \multicolumn{7}{|c|}{ MS of grouped analysis in high-tech environment } \\
\hline Progenies/Exp. & 222 & $301.479 * *$ & $229.873 * *$ & $22.633 * *$ & $516.019 * *$ & $0.315 * *$ \\
\hline Mean error & 476 & 91.655 & 73.929 & 6.213 & 228.098 & 0.139 \\
\hline Within progenies & 2758 & 312.886 & 254.792 & 25.385 & - & - \\
\hline Progenies mean & - & 261.19 & 158.77 & 22.67 & 54.36 & 2.14 \\
\hline CV (\%) & - & 3.66 & 5.42 & 10.99 & 29.08 & 17.37 \\
\hline \multicolumn{7}{|c|}{ MS of grouped analysis in low-tech environment } \\
\hline Progenies/Exp. & 190 & $383.744 * *$ & $230.189 * *$ & $32.274 * *$ & $345.483 * *$ & $0.101 * *$ \\
\hline Controls x Exp. & 7 & 143.502 & 42.606 & 3.265 & 36.324 & 0.105 \\
\hline Mean error & 412 & 117.404 & 73.407 & 6.245 & 145.683 & 0.039 \\
\hline \multicolumn{7}{|c|}{ MS of joint analysis for both technology levels } \\
\hline Tech. Level (TL) & 1 & $12159.153 * *$ & $13343.951 * *$ & $35.182 * *$ & $39850.602 * *$ & $1.492 * *$ \\
\hline Progenies/Exp & 190 & $580.859 * *$ & $373.842 * *$ & $47.051 * *$ & $585.017 * *$ & $0.231 * *$ \\
\hline Progenies/Exp x TL & 190 & 109.935 & 80.645 & 7.872 & 197.298 & $0.184 * *$ \\
\hline Mean error & 824 & 106.900 & 74.324 & 6.939 & 194.928 & 0.093 \\
\hline Progenies mean & - & 251.75 & 148.48 & 23.24 & 68.69 & 1.84 \\
\hline CV (\%) & - & 4.11 & 5.81 & 11.34 & 20.33 & 16.53 \\
\hline
\end{tabular}

** - Significant at $1 \%$ probability level. 
and $14.8 \%$ /cycle, respectively, for high and low-tech environments. For $\mathrm{PH}$, the expected gains with selection between half-sibs (4.6\% for high, and 5.6\% for low-tech environments) were similar to those reported by Kist et al. (2010) for the population MPA1.

For GY, the expected gain with mass selection in high-tech environment was $7.7 \%$, which is equivalent to the gain of $7.9 \%$ reported by Souza et al. (2018) in three semi-exotic populations, and higher than that reported by Andrade and Miranda Filho (2008) (4.17\%). In low-tech environment, it was calculated a 50\% lower expected gain. In selection between progenies, it is expected a gain twice as the mass selection gain, both for high and low-tech environments. In this type of selection, gain in low-tech environment (7.3\%) is equivalent to that obtained by Andrade and Miranda Filho (2008) (6.98\%), and the gain in high-tech environment (14.8\%) is close to that obtained by Candido and Andrade (2008) for a dwarf population, in densities of 57,800 and 80,000 plants/ha (16.0 and 19.2\%, respectively). Araújo et al. (2005) estimated lower gains (8.1 and 9.0\%) for the population CMS 39, at $0.5 \mathrm{~m}$ and $0.9 \mathrm{~m}$ spacing, as well as Kist et al. (2010), with estimates of $3.9 \%, 5.7 \%$ and $5.0 \%$ for the population MPA1, in a convergent-divergent selection scheme. In this study, gains with mass and selection between progenies are practically the same, when considering the time and labor required to carry out a selection cycle by both methods. In this case, it is expected that the use of half-sib

Table 3. Genetic parameter estimates for each technology level, and for joint analysis for plant height (PH), ear height (EH), tassel branches number (TB), erect plants (EP), and grain yield (GY) for Flintisa Composite of maize

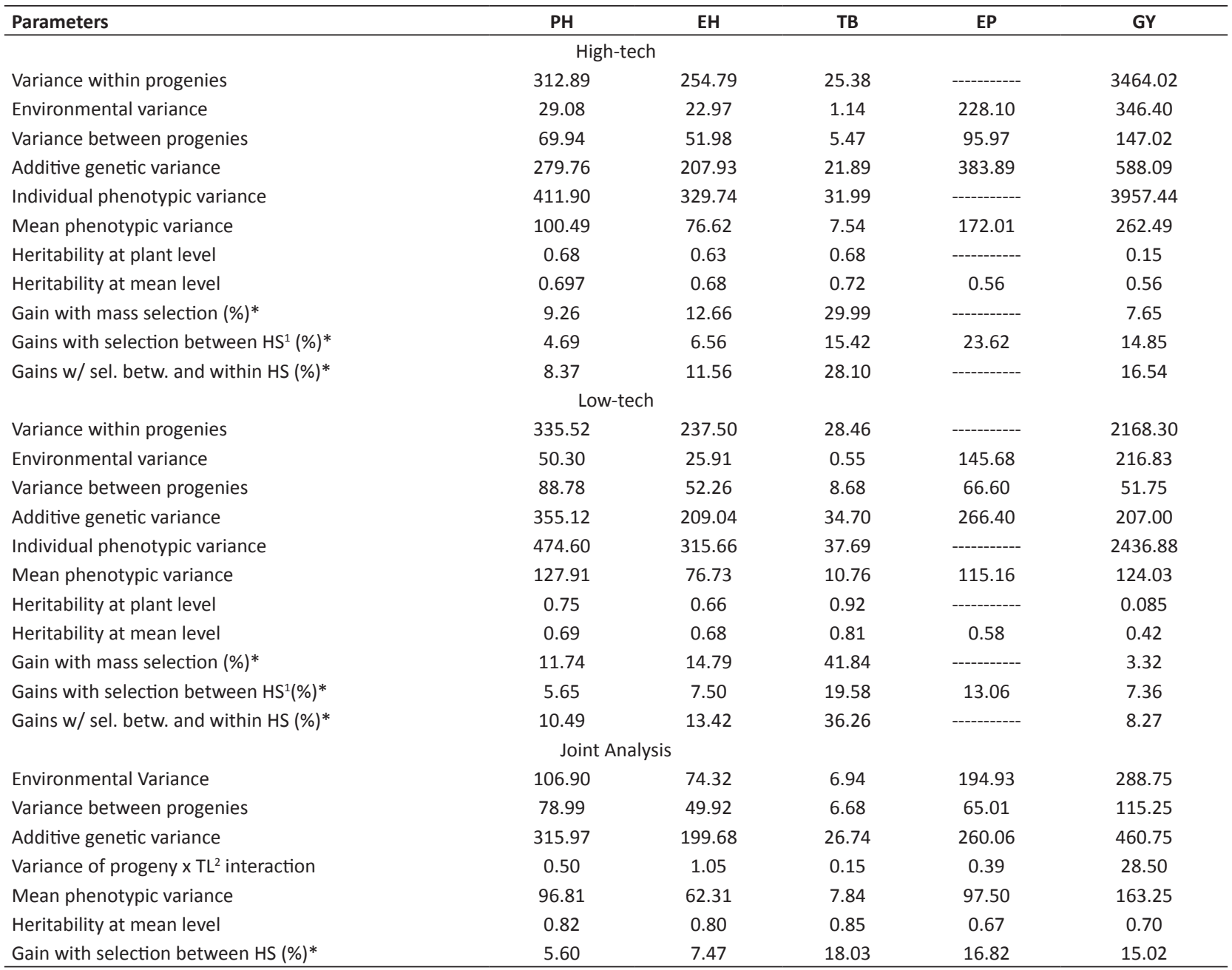

${ }^{1}$ Half-sib; ${ }^{2}$ Technological level; * Intensity of $10 \%$ for all selection modalities; Selection for both sexes between progenies, and one sex within progenies and in mass selection. 
selection with $\mathrm{S}_{1}$ recombination surpasses mass selection in efficiency, which usually occurs for traits of low heritability. In low-tech environment, the expected gain with selection between progeny was lower than high-tec (3.3\%). However, with selection between and within half-sib progenies, it is expected a gain of $8.3 \% / c y c l e$, showing that, in this case, it will be the best method to be used, as suggested by Candido and Andrade (2008). In the most stressful conditions, the discrimination between superior and inferior genotypes is less accurate, probably due to the limitation of the expression of many genes with additive effects, which requires more accurate techniques for selection. Thus, it is noted that obtaining considerable gains in yield depends on the use of inbreeding in the selection unit, in the evaluation unit, or in both, as in the case of the selection between $\mathrm{S}_{1}$ progenies, when all the additive variance is exploited.

The expected gain with mass selection for TB in low-tech environment (41.8\%) was 1.4 times higher than in hightech, and also higher than expected for the varieties Centralmex (23.2\%), Dentado composite (10.9\%), Flint composite (13.4\%) (Geraldi et al. 1985), Esalq-PB1 (27.4\%) (Andrade and Miranda Filho 2008) and three semi-exotic populations (1.4, 0.03 and $0.22 \%$ ) (Souza et al. 2018).

The correlation coefficients (Table 4) and the correlated responses (Table 5) indicated genetic independence of $\mathrm{PH}$ and $\mathrm{EH}$ in relation to TB and EP. This indicates that although the high lodging may be due to $\mathrm{PH}$ and $\mathrm{EH}$, this is an environmental relationship. Thus, the high population would have caused some etiolating, making the stems more fragile.

Due to the high correlation between $\mathrm{PH}$ and EP, selection for lower ear height is sufficient, in this population, to assist in the improvement of plant architecture, as indicated by Tengan et al. (2012) in backcross populations between not opaque and opaque-2 maize and Izzam et al. (2017). On the other hand, under high-tech environment, correlations of TB with EP and with GY are negative, indicating that selection for less tassel branches will provide a decrease in lodging and an increase in GY. As TB has high heritability, it can be an excellent selection trait to increase yield, especially in more advanced selection cycles, when the genetic variance for yield is lower. With mass selection, this possibility of gains with indirect selection is in agreement with the studies of Falconer and Mackay (1996), since there is high additive genetic correlation between traits, low heritability in the main trait (GY), and high heritability in the secondary trait (TB). Sohail et al. (2018) also found favorable correlations between physiological traits and GY in the CZP-132011 population.

Selection based on EP is also a good possibility to bring about positive correlated response in yield, almost equal to the expected gain with direct selection. This is done indirectly, since lodged and/or broken plants are rejected at any selective process, helping to maximize the gain in GY.

There was significance at $1 \%$ probability for the technology level variation source in all the traits. However, only GY had significant interaction between progeny and technology levels. Vencovsky and Barriga (1992) consider that, in any population with genetic variability, there will be genotype $x$ environment interaction. The relative magnitude of this interaction subsidizes the breeder in relation to the strategy of choosing genotypes of broad adaptation or of restricted

Table 4. Estimates of the coefficients of additive genetic correlation (above the diagonal) and phenotypic correlation at mean level (below the diagonal), between plant height (PH), ear height (EH), tassel branches number (TB), erect plants (EP) and grain yield (GY) for Flintisa Composite in high and low technology environments

\begin{tabular}{|c|c|c|c|c|c|}
\hline & $\mathrm{PH}$ & $\mathrm{EH}$ & TB & EP & GY \\
\hline & & & High-tech & & \\
\hline $\mathrm{PH}$ & --------- & 0.73 & 0.02 & 0.04 & 0.21 \\
\hline $\mathrm{EH}$ & 0.73 & ------------- & 0.07 & 0.02 & 0.31 \\
\hline TB & 0.04 & 0.02 & ------------ & -0.35 & -0.32 \\
\hline EP & 0.02 & 0.02 & -0.25 & -------------- & 0.50 \\
\hline GY & 0.17 & 0.26 & -0.24 & 0.37 & --------.. \\
\hline $\mathrm{PH}$ & --------- & 0.93 & 0.09 & 0.02 & 0.38 \\
\hline $\mathrm{EH}$ & 0.87 & --------- & 0.18 & -0.03 & 0.33 \\
\hline TB & 0.08 & 0.16 & --------- & -0.11 & 0.08 \\
\hline $\mathrm{EP}$ & -0.02 & -0.05 & -0.08 & --------- & -0.06 \\
\hline GY & 0.28 & 0.23 & 0.07 & 0.04 & -------- \\
\hline
\end{tabular}


Table 5. Estimates of correlated responses in plant height (PH), ear height (EH), tassel branches number (TB), erect plants (EP), and grain yield (GY), with selection between and within half-sib progenies and mass selection (10\% intensity) in Flintisa Composite, in high and low-tech environments

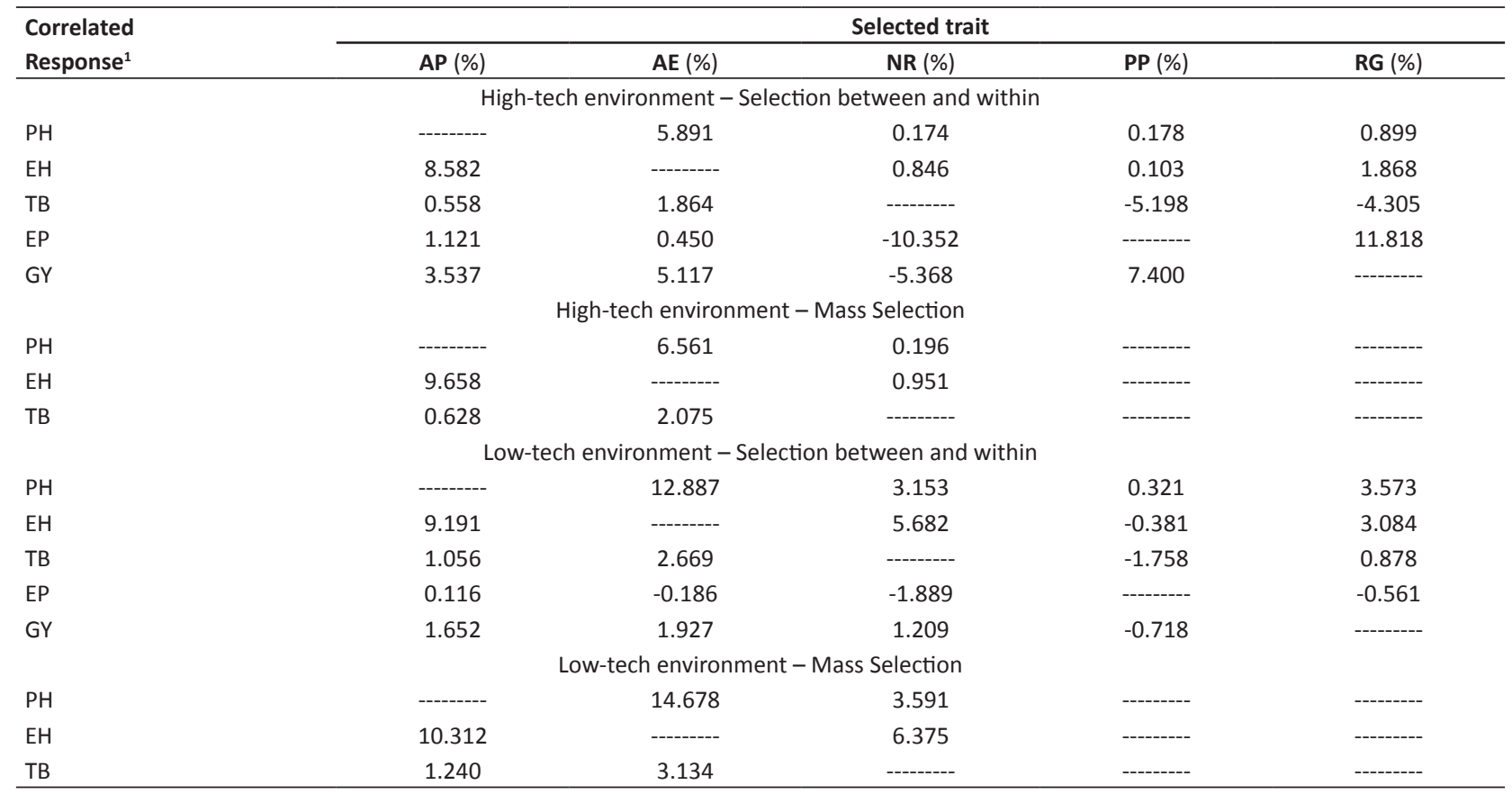

${ }^{1}$ Selection for both sexes between progenies and one sex within progenies and in mass selection.

adaptation to specific environments. Although the influence of the interaction in high heritability traits is usually lower, Carvalho and Souza (2007) and Aci et al. (2018) state the importance of evaluating yield in various environments, in order to improve the efficiency of the selection process, and to obtain more accurate estimates of variance components.

The expected gain with selection between half-sib, taking into account the means of the two environments, is equivalent to that expected with the specific selection for each environment (Table 3) for PH, EH and TB. For EP, the expected gain with joint selection is $\mathbf{2 8 . 8 \%}$ lower than that expected with selection in high-tech, and $28.7 \%$ higher than that expected in low-tech environment. These results and the non-significance of the progenies $x$ technology levels interaction indicate that in the traits related to plant architecture (PH, EH and TB) and EP, selection may be carried out in any of the environments, with valid results for both. The comparison between the estimates of the progenies variance and the progenies $x$ technology levels interaction (Table 2) shows that the latter is lower than the former for $\mathrm{PH}, \mathrm{EH}, \mathrm{TB}$ and $\mathrm{EP}$. For GY, progenies variance was four times higher than the interaction variance. However, since the interaction variance was significant, it is suggested that separate programs are carried out for better adaptation to specific environments. This does not exclude the possibility of achieving progeny that adapt to both environments, with expected gains equivalent to the selection for high-tech environment and twice as the low-tech environment (Table 3). However, the evaluation in both environments is still required, so there is no divergence between the progenies selected in each environment. Thus, it is recommended to carry out separate programs for GY, since the selection process by grouping the two environments does not reduce costs. Moreover, there is the possibility of having sharp decrease in gain with joint program, as genetic variability decreases over the selection cycles.

\section{REFERENCES}

Aci MM, Lupini A, Mauceri A, Morsli A, Khelifi L and Sunsen F (2018) Genetic variation and structure of maize populations from Saoura and Gourara oasis in Algerian Sahara. BMC Genetics 19: 1-10.
Andrade JAC and Miranda Filho JB (2008) Quantitative variation in the tropical maize population, ESALQ-PB1. Scientia Agricola 65: 174-182.

Araújo PA, Santos VS, Bison O and Souza JC (2005) Avaliação de famílias de meios-irmãos de milho em diferentes espaçamentos entre linhas. Revista Brasileira de Milho e Sorgo 4: 428-435. 
Candido LS and Andrade JAC (2008) Breeding potential of maize composite Isanão VF1 in small spacing in the second growing season. Crop Breeding and Applied Biotechnology 8: 56-64.

Carvalho HWL and Souza EM (2007) Ciclos de seleção de progênies de meios-irmãos do milho BR 5011 Sertanejo. Pesquisa Agropecuária Brasileira 42: 803-809.

Carvalho HWL Leal MLS Santos MX and Souza EM (2003) Estimativas de parâmetros genéticos na população de milho CPATC-3 em dois locais de Sergipe. Pesquisa Agropecuária Brasileira 38: 73-78.

Falconer DS and Mackay TFC (1996) Introduction to quantitative genetics. Person Education Limited, Harlow, 464p.

Faluba JS, Miranda GV, Lima RV, Souza LV, Debem EA and Oliveira AMC (2010) Potencial genético da população de milho UFV 7 para o melhoramento em Minas Gerais. Ciência Rural 40: 1250-1256.

Freitas Júnior SP, Amaral Júnior AT, Rangel RM and Viana AP (2009) Genetic gains in popcorn by full-sib recurrent selection. Crop Breeding and Applied Biotechnology 9: 1-7.

Gardner CO (1961) An evaluation of effects of mass selection and seed irradiation with thermal neutrons on yield of corn. Crop Science 1: 241-245.

Geraldi IO, Miranda Filho JB and Vencovsky R (1985) Estimates of genetic parameters for tassel characters in maize (Zea mays L.) and breeding perspectives. Maydica 30: 1-14.

Hallauer AR, Carena MJ and Miranda Filho JB (2010) Quantitative genetics in maize breeding. Springer, New York, 463p.

Izzam, A, Rehman H, Sohail A, Ali S and Hussain MQ (2017) Genetic variability and correlation studies for morphological and yield traits in maize (Zea mays L.). Pure and Applied Biology 6: 1234-1243.

Khan AS, Ullah H, Shahwar D, Fahad S, Khan N, Yasir M, Wahid F, Adnan $M$ and Noor M (2018) Heritability and correlation analysis of morphological and yield traits in maize. Journal of Plant Biology and Crop Research 2: 1-8.

Kist V, Ogliari JB, Miranda Filho JB and Alves AC (2010) Genetic potential of maize population from southern Brazil for the modified convergentdivergent selection scheme. Euphytica 176: 25-36.

Oliveira AS, Miranda Filho JB and Reis EF (2015) Variability and inbreeding in semi-exotic maize populations. Genetic and Molecular Research 14: 1184-1199.

Pimentel-Gomes F and Garcia CH (2002) Estatística aplicada a experimentos agronômicos e florestais: exposição com exemplos e orientações para uso de aplicativos. FEALQ, Piracicaba, 309p.

Reis MC, Pádua JMV, Abreu GB, Guedes FL, Balbi RV and Souza JC (2014) Estimates for genetic variance components in reciprocal recurrent selection in populations derived from maize single-cross hybrids. The Scientifc World Journal 2014: 1-7.

Scapim CA, Carvalho CGP and Cruz CD (1995) Uma proposta de classificação dos coeficientes de variação para a cultura do milho. Pesquisa Agropecuária Brasileira 30: 683-686.

Shahrokhi M, Khorasani SK and Ebrahimi A (2013) Generation mean analysis: a case of yield and yield components in ksc704 maize (Zea mays L.) generations. International Journal of Agronomy and Plant Production 4: 2686-2693.

Singh AK, Mishra SP and Parihar R (2018) Studies on genetic variability parameters on grain yield and its yield attributing traits in maize (Zea mays L.). International Journal of Current Microbiology and Applied Sciences 7: 1261-1266.

Soares MO, Miranda GV, Guimarães LJM, Marriel IE and Guimarães CT (2011) Parâmetros genéticos de uma população de milho em níveis contrastantes de nitrogênio. Revista Ciência Agronômica 42: 168-174.

Sohail A, Rahman H, Hussain Q, Hadi F, Ullah U, Khan W, Khan MA, Asad M, Yousafzai Z, Sami S and Uddin S (2018) Genetic variability, heritability and correlation studies in half sib recurrent families of Cimmyt maize population CZP-132011. ARPN Journal of Agricultural and Biological Science 13: 106-112.

Souza AC, Miranda Filho JB, Oliveira AS, Pinto JFN, Silva CM and Reis EF (2018) Genetic variability and expected gain in three maize populations. Revista Brasileira de Milho e Sorgo 17: 135-146.

Souza Júnior CL, Geraldi IO and Zinsly JR (1985) Influence of tassel size on the expression of prolificacy in maize (Zea mays L.). Maydica 30: $321-328$

Tengan KML, Obeng-Antwi K and Akromah R (2012) Genetic variances, heritability, and correlation studies on selected phenotypic traits in a backcross breeding program involving normal and opaque-2 maize. Agriculture and Biology Journal of North America 3: 287-291.

Vencovsky R (1987) Herança quantitativa. In Paterniani E and Viégas GP (ed.) Melhoramento e produção do milho. Fundação Cargill, Campinas, p. 135-214.

Vencovsky R and Barriga P (1992) Genética biométrica no fitomelhoramento. Revista Brasileira de Genética, Ribeirão Preto, $496 \mathrm{p}$.

(cc) EY This is an Open Access article distributed under the terms of the Creative Commons Attribution License, which permits unrestricted use, distribution, and reproduction in any medium, provided the original work is properly cited. 